\title{
Mycobacterium septicum sp. nov., a new rapidly growing species associated with catheter-related bacteraemia
}

\author{
Mark F. Schinsky, ${ }^{1,5}$ Michael M. McNeil, ${ }^{1}$ Anne M. Whitney, ${ }^{1}$ \\ Arnold G. Steigerwalt, ${ }^{1}$ Brent A. Lasker, ${ }^{2}$ Margaret M. Floyd, ${ }^{3}$ \\ Geoffrey G. Hogg, ${ }^{4}$ Don J. Brenner ${ }^{1}$ and June M. Brown ${ }^{1}$
}

Author for correspondence: June M. Brown. Tel: +1 404639 3491. Fax: +1 4046393123. e-mail: jmb6@cdc.gov

\footnotetext{
1,2,3 Meningitis and Special Pathogens Branch ${ }^{1}$ and Mycotic Diseases Branch2, Division of Bacterial and Mycotic Diseases and Tuberculosis/ Mycobacteriology Branch, Division of AIDS, STD and TB Laboratory Research ${ }^{3}$, National Center for Infectious Diseases, Centers for Disease Control and Prevention, Public Health Service, US Department of Health and Human Services, Atlanta, GA 30333, USA

4 Mycobacterium Reference Laboratory, Victorian Infectious Diseases Reference Laboratory, Melbourne, Australia 3052

5 College of Physicians \& Surgeons, Columbia University, New York, NY 10032, USA
}

\begin{abstract}
Rapidly growing mycobacteria are capable of causing several clinical diseases in both immunosuppressed and immunocompetent individuals. A previously unidentified, rapidly growing mycobacterium was determined to be the causative agent of central line sepsis in a child with underlying metastatic hepatoblastoma. Four isolates of this mycobacterium, three from blood and one from the central venous catheter tip, were studied. Phenotypic characterization, HPLC and genetic analysis revealed that while this organism most closely resembled members of the Mycobacterium fortuitum complex and Mycobacterium senegalense, it differed from all previously described species. Phenotypic tests useful in differentiating this species from similar rapidly growing mycobacteria included: growth at $42{ }^{\circ} \mathrm{C}$, hydrolysis of acetamide, utilization of citrate, production of arylsulfatase (3-d), acidification of o-mannitol and i-myo-inositol, and susceptibility to erythromycin, vancomycin and tobramycin. The name Mycobacterium septicum is proposed for this new species. The type strain has been deposited in Deutsche Sammlung von Mikroorganismen und Zellkulturen as DSM $44393^{\top}$ and in the American Type Culture Collection as strain ATCC 700731'.
\end{abstract}

Keywords: Mycobacterium septicum sp. nov., Mycobacterium fortuitum complex, sepsis/bacteraemia, DNA-DNA hybridization, 16S rRNA gene sequence

\section{INTRODUCTION}

Rapidly growing mycobacteria have been increasingly recognized as a cause of human infection during the last two decades. Specifically, the diagnoses of Mycobacterium fortuitum complex infections have risen in part because of an increased awareness of their potential as human pathogens. In the immunosuppressed patient, these organisms can cause serious infections such as catheter-related bacteraemia or disseminated disease. Disseminated disease can be lifethreatening, although it usually presents as a chronic

Abbreviations: NCCLS, National Committee for Clinical Laboratory Standards; RRT, relative retention times.

The GenBank accession number for the 16S rRNA sequence of Mycobacterium septicum $\mathrm{W}^{4} 964^{\top}$ is AF111809. illness associated with skin abscesses, cellulitis and multiple subcutaneous nodular lesions that primarily involve the extensor surfaces of the arms and legs (Sack, 1990).

It has become apparent that the genus Mycobacterium is more diverse than was previously realized and includes a significant number of emerging pathogens (Domenech et al., 1997; Haas et al., 1997; Wallace et al., 1991). Recently, an unidentified Mycobacterium species was isolated from three blood cultures and a central venous catheter tip after its removal from a child diagnosed with metastatic hepatoblastoma (Hogg et al., 1999). These isolates were phenotypically and genetically identical. By standard biochemical tests, they were phenotypically similar to the $M$. fortuitum complex and could not be differentiated from related members of the complex on the basis of 
mycolic acid profiles obtained using HPLC. The $16 \mathrm{~S}$ rRNA gene of a representative isolate was sequenced and showed that these isolates were related but not identical to $M$. fortuitum, Mycobacterium peregrinum and Mycobacterium senegalense. An extensive polyphasic study that used additional biochemical tests, antimicrobial susceptibility analysis, ribotyping and DNA relatedness indicated that this micro-organism was not a species of $M$. fortuitum, M. peregrinum or $M$. senegalense. The results of this study showed that this previously unidentified mycobacterium belongs to a new species for which the name Mycobacterium septicum is proposed.

\section{METHODS}

Bacterial strains. Isolates W4962, W4963 and W5064 were cultured from the blood of a 2-year-old child with metastatic hepatoblastoma. Isolate W4964 ${ }^{\mathrm{T}}$ was cultured from the tip of the patient's centrally placed Hickman catheter upon its removal (Hogg et al., 1999). M. fortuitum ATCC $6841^{\mathrm{T}}$ and $M$. peregrinum ATCC $14467^{\mathrm{T}}$ were provided by Richard J. Wallace, Jr, Department of Microbiology, The University of Texas Health Sciences Center at Tyler, TX, USA. $M$. senegalense ATCC $35796^{\mathrm{T}}$ was obtained from the ATCC.

Phenotypic analysis. Macroscopic morphological studies were performed on colonies grown on heart infusion agar with rabbit blood (blood agar) (BBL Prepared Media, Becton-Dickinson, Microbiology Systems) and incubated at $35^{\circ} \mathrm{C}$ for $2 \mathrm{~d}$. A stereomicroscope $(10 \times)$ was used to determine the presence of aerial mycelium. Microscopic morphology and acid-fastness were studied by using Gram and modified Kinyoun acid-fast stains, respectively (Berd, 1973). Standard biochemical tests routinely used in Actinomycete and Mycobacteriology Laboratories at the Centers for Disease Control and Prevention were performed (Berd, 1973; Silcox et al., 1981). In addition, hydrolysis of acetamide (BBL), utilization of citrate (BBL) and growth at $42{ }^{\circ} \mathrm{C}$ were tested using the methods of Wallace et al. (1991).

Antimicrobial susceptibility tests were performed by a previously described broth microdilution method using cation-supplemented Mueller-Hinton broth (Wallace et al., 1991). The drugs tested were amikacin, amoxicillin-clavulanate, ampicillin, cefotaxime, ceftriaxone, ciprofloxacin, doxycycline, erythromycin, imipenem, minocycline, sulfamethoxazole, trimethoprim-sulfamethoxazole and vancomycin. Plates were incubated for $72 \mathrm{~h}$ at $35^{\circ} \mathrm{C}$. Since the methods of testing and the breakpoints for resistance for rapidly growing mycobacteria have not been standardized or approved by the National Committee for Clinical Laboratory Standards (NCCLS), the breakpoints for resistance used were those of the NCCLS for organisms that grow aerobically (National Committee for Clinical Laboratory Standards, 1997). Additionally, antimicrobial susceptibilities were determined by using a disk-diffusion method for cefamandole $(30 \mu \mathrm{g})$, tobramycin $(10 \mu \mathrm{g})$, streptomycin $(10 \mu \mathrm{g})$, gentamicin $(10 \mu \mathrm{g})$, neomycin $(30 \mu \mathrm{g})$ and kanamycin $(30 \mu \mathrm{g})$, as previously described (Grange \& Stanford, 1974). The zone sizes for resistance used were those of Grange \& Stanford (1974).

HPLC. The mycolic acid pattern analysis was performed according to the procedure of Butler et al. (1991). Briefly, whole cells were saponified in methanolic potassium hydroxide solution. After acidification, chloroform extracts containing the mycolic acids were separated from the cellular materials and mycolic acids were derivatized to bromophenacyl esters. Chromatography was performed with a Beckman chromatograph (Beckman Instruments) controlled by Beckman System Gold software and equipped with a Beckman reverse phase C-18 column $(4.6 \times 75 \mathrm{~mm})$, a Beckman column heater $\left(35 \pm 1^{\circ} \mathrm{C}\right)$ and a variable wavelength UV detector adjusted to $260 \mathrm{~nm}$. A 10-min methanol and methylene chloride gradient was used as previously described (Butler et al., 1996). Patterns generated with this method were visually matched to HPLC patterns of authentic species by using the relative retention time (RRT) ratios as calculated by the software. These ratios were derived using a high-molecular-weight standard (Ribi ImmunoChem Research) as the reference peak (Butler et al., 1992)

DNA purification. Strains were subcultured from Lowenstein-Jensen slants into 1.51 Mueller-Hinton broth containing $22.5 \mathrm{~g}$ glycine (Sigma) and $7.5 \mathrm{ml}$ Tween 80 (Sigma) and grown for $1-2 \mathrm{~d}$ at $35^{\circ} \mathrm{C}$ before being harvested by centrifugation. DNA was purified from lysed protoplasts as described previously by Lasker et al. (1992). To obtain optimal yields, repeat extractions were performed with of $20 \%$ (w/v) SDS (Roche) extractions to improve the DNA yield as adapted from Loeffelholz \& Scholl (1989).

Ribotyping. Genomic DNA (1-2 $\mathrm{mg} \mathrm{m}^{-1}$ ) was digested with $20 \mathrm{U} \mathrm{SmaI}$ and SalI (Roche) for $8 \mathrm{~h}$ at $35^{\circ} \mathrm{C}$ in the buffer recommended by the manufacturer. DNA fragments were separated by electrophoresis in a $0.85 \%(\mathrm{w} / \mathrm{v})$ agarose gel (GIBCO). DNA fragments were then transferred to a nylon membrane (Nytran; Schleicher \& Schuell) and were hybridized with a digoxigenin-labelled set of five oligonucleotides at $35^{\circ} \mathrm{C}$ as previously described (Regnault et al., 1997). rDNA-containing fragments were visualized according to the 'Genius' kit (Roche) protocol.

$16 \mathrm{~S}$ rRNA sequencing. Purified genomic DNA was diluted to $1 \mu \mathrm{g} \mathrm{ml}^{-1}$ in sterile water. Diluted DNA $(10 \mu \mathrm{l})$ was used in a $100 \mu \mathrm{l}$ PCR containing $200 \mu \mathrm{M}$ dNTPs, $1 \mathrm{mM} \mathrm{MgCl}_{2}, 1 \times$ PCR buffer II (Perkin-Elmer), $0 \cdot 1 \mu \mathrm{M}$ M104F primer (5'-GAACGGGTGAGTAACACG-3'), $0 \cdot 1 \mu \mathrm{M}$ M1510R primer (5'-GGCTACCTTGTTACGACTT-3') and $2.5 \mathrm{U}$ AmpliTaq DNA polymerase (Perkin-Elmer). M104F and M1510R were derived from mycobacterial $16 \mathrm{~S}$ genes published in GenBank. The parameters for amplification were $94{ }^{\circ} \mathrm{C}$ for $5 \mathrm{~min}, 35$ cycles of $15 \mathrm{~s}$ at $94{ }^{\circ} \mathrm{C}, 15 \mathrm{~s}$ at $50{ }^{\circ} \mathrm{C}$, $1.5 \mathrm{~min}$ at $72{ }^{\circ} \mathrm{C}$, and a $72{ }^{\circ} \mathrm{C}$ extension for $5 \mathrm{~min}$ before cooling to $4{ }^{\circ} \mathrm{C}$.

The results of the PCR reaction were checked by running $10 \mu \mathrm{l}$ of each reaction mix on a $1 \%(\mathrm{w} / \mathrm{v})$ agarose gel. The $16 \mathrm{~S}$ DNA from isolate $\mathrm{W} 4964^{\mathrm{T}}$ was then purified and concentrated by using a PCR Purification kit from Qiagen; $60 \mathrm{ng}$ PCR product was used for each sequencing reaction. The sequencing reaction consisted of $16 \mathrm{~S}$ DNA, $8 \mu \mathrm{l}$ ABI PRISM dye terminator cycle sequencing ready reaction kit (Perkin-Elmer) and 3.2 pmol of primer; sterile water was added to a final amount of $20 \mu \mathrm{l}$. The primer set used for sequencing was derived from those designed by Stackebrandt \& Charfreitag (1990). The manufacturer's instructions for the cycle sequencing kit were followed for the thermal cycler conditions. The extension products from each sequencing reaction were purified through a Centrisep column (Princeton Separations) and dried in a vacuum centrifuge for $20 \mathrm{~min}$. Amplifications were performed on a Perkin-Elmer 9600 thermocycler.

The sequencing reactions were resolved on a $4.2 \%(\mathrm{w} / \mathrm{v})$ 
acrylamide/8 M urea gel electrophoresed on an ABI 377 automated sequencer (Perkin-Elmer). The sequence data were edited and compiled by using the Wisconsin Sequence Analysis Package (Genetics Computer Group). The 16S sequences were aligned by using the Wisconsin Sequence Analysis Package program PILEUP with 16S sequences of 18 Mycobacterium spp. and an outgroup sequence retrieved from GenBank. The multiple sequence alignment was edited manually. The edited alignment was used in PHYLIP (version 3.5, J. Felsenstein) to derive a phylogenetic dendrogram using the nucleotide substitution model of Jukes \& Cantor (1969) and the neighbour-joining method of Saitou \& Nei (1987). The plotfile from PHYLIP 3.5 was reformatted for the HP Laserjet 4 printer by using PRINTGL software (Ravitz Software).

DNA relatedness and $\mathbf{G}+\mathbf{C}$ determination. DNA labelling and DNA relatedness experiments by the hydroxyapatite method have been described previously (Brenner et al., 1982). DNA was labelled in vitro with $\left[{ }^{32} \mathrm{P}\right] \mathrm{dCTP}$ by using a nick-translation kit (GIBCO). The temperature used for optimal hybridization was $75^{\circ} \mathrm{C}$ and the percentage divergence was calculated to the nearest $0.5 \%$ (Brenner et al., 1983). The $\mathrm{G}+\mathrm{C}$ content of DNA from $M$. septicum isolate W4964 ${ }^{\mathrm{T}}$ was determined spectrophotometrically by using the thermal denaturation method as previously described (Mandel et al., 1970).

\section{RESULTS AND DISCUSSION}

\section{Phenotypic properties}

The four isolates from the patient all exhibited the same phenotypic profile. Microscopic morphological studies showed that they were Gram-positive, pleomorphic coccobacilli, lacking spores and capsules, that frequently exhibited longer filamentous forms. No true branched filaments were observed. Upon examination with a low-power stereomicroscope, colonies of cultures incubated on blood agar plates at $35^{\circ} \mathrm{C}$ for $2 \mathrm{~d}$ showed slightly beige, cerebriform and irregularedged colonies (1 $\mathrm{mm}$ in diameter) that did not demonstrate aerial hyphae. The isolates were acid-fast by the modified Kinyoun method.

The isolates grew on Lowenstein-Jensen medium at $35^{\circ} \mathrm{C}$ in less than $7 \mathrm{~d}$; grew at $28{ }^{\circ} \mathrm{C}$ in $5 \% \mathrm{NaCl}$ and on MacConkey agar without crystal violet; were negative for growth in lysozyme, utilization of citrate and hydrolysis of acetamide; and were positive for iron uptake, nitrate reduction and 14-d arylsulfatase production. The isolates produced acid from D-fructose, D-glucose, glycerol, i-myo-inositol, Dmannitol, D-mannose, salicin, D-trehalose and Dxylose. They did not produce acid from adonitol, Larabinose, cellobiose, dulcitol, i-erythritol, galactose, lactose, maltose, melibiose, raffinose, L-rhamnose, Dsorbitol, starch or sucrose. All of the isolates were resistant to ampicillin, cefamandole, cefotaxime, ceftriaxone and streptomycin. The isolates showed susceptibility to the remaining 14 antimicrobial agents tested.

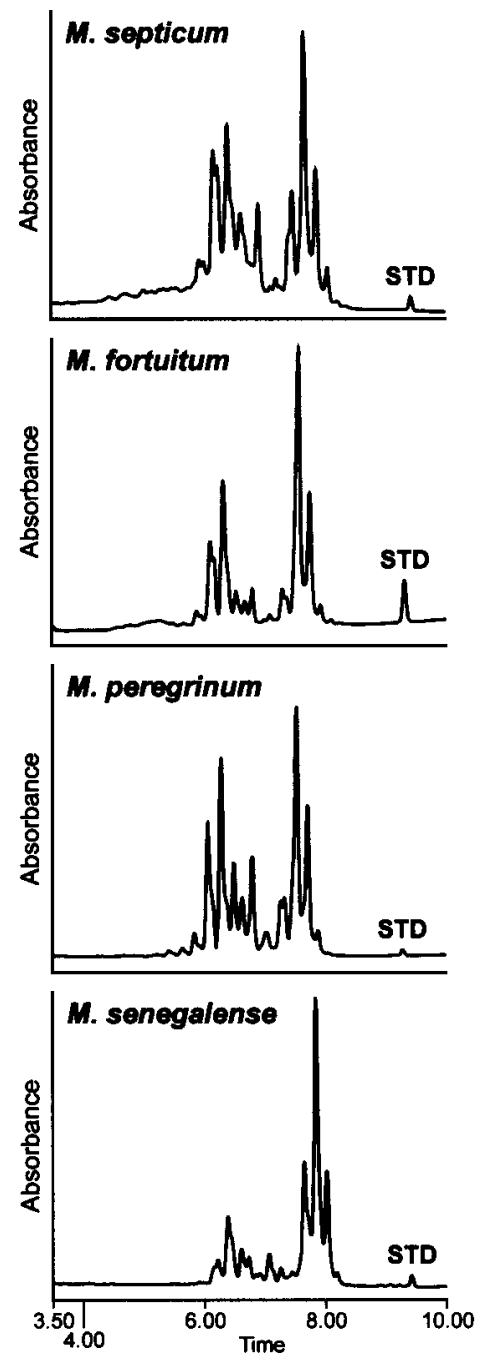

Fig. 1. Comparison of representative mycolic acid profiles as determined by HPLC of Mycobacterium septicum (four isolates), Mycobacterium fortuitum, Mycobacterium peregrinum and Mycobacterium senegalense. The last peak, labelled STD, corresponds to the internal standard.

\section{HPLC analysis}

RRT ratios $( \pm 0.01 \mathrm{~min})$ were used to compare corresponding peaks among chromatograms (Butler et al., 1992). The mycolates for the isolates appeared within the expected range for the rapidly growing mycobacteria, which elute after 5 min by the HPLC method. Comparison of the RRT ratios for these isolates with strains of $M$. fortuitum, $M$. peregrinum and $M$. senegalense revealed that these species are not easily differentiated by HPLC profiles (Fig. 1). The RRT ratios for initial eluting peaks for each of the species studied were the same, but $M$. senegalense exhibited some differences in the RRT ratios for the late eluting peaks. The late eluting peaks for the isolates, M. fortuitum and M. peregrinum exhibited the same RRT with slight differences in relative heights. Visual recognition by HPLC clearly distinguished 


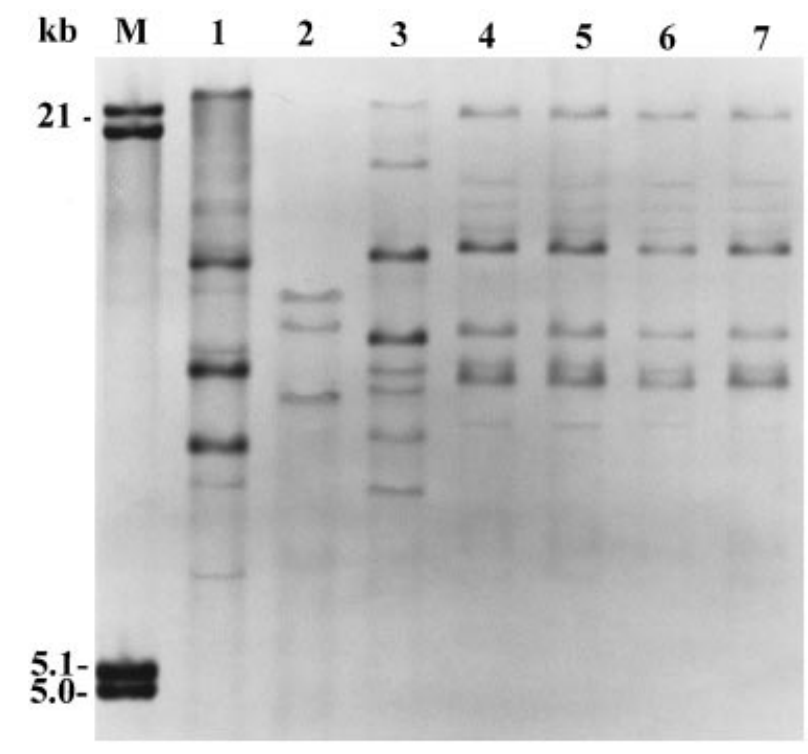

Fig. 2. Ribotype patterns from Sall-digested genomic DNA of Mycobacterium septicum and the other members of the Mycobacterium fortuitum complex. Lanes: $M, \lambda$-DNA molecular size marker digested with EcoRI and HindIII; 1, Mycobacterium senegalense ATCC $35796^{\top}$; 2, Mycobacterium peregrinum ATCC $14467^{\top} ; 3$, Mycobacterium fortuitum ATCC $6841^{\top} ; 4-7$, Mycobacterium septicum sp. nov. isolates W4962, W4963, $\mathrm{W}^{4964}{ }^{\top}$ and $\mathrm{W} 5064$, respectively. Molecular sizes are given in kilobases $(\mathrm{kb})$.

these isolates from Mycobacterium chelonae and Mycobacterium abscessus, which were previously included in the $M$. fortuitum complex. HPLC analysis alone was not conclusive; therefore, additional test methods were required to differentiate the isolates from the members of the $M$. fortuitum complex.

\section{Genotypic description and evaluation}

Ribotyping is useful in species identification, especially when strains are difficult to analyse phenotypically, by detecting minor genetic differences and providing information for species determination on the basis of common bands (Kiehlbauch et al., 1991). Moreover, ribotyping has been a potent molecular technique in species differentiation, particularly when combined with other genetic tools such as 16S rRNA gene sequencing and DNA-DNA hybridization (Popovic et al., 1993). As shown in Fig. 2, SalI-digested genomic DNA hybridized with five digoxigenin-labelled oligonucleotides gave identical hybridization bands between the catheter tip and the blood isolates. This banding pattern differed significantly from those of $M$. fortuitum, $M$. peregrinum and $M$. senegalense. Similar results were obtained with $S m a I$ (results not shown). The isolate obtained from the catheter tip and the three blood isolates were identical in phenotypic tests including morphological and physiological tests and antimicrobial susceptibilities; these four isolates had identical RFLP patterns of the chromosomal DNA digested with SalI, SmaI, PvuII and PstI (results not shown) demonstrating they are of clonal origin. In addition, the catheter tip and the three blood isolates differed from $M$. fortuitum third biovariant complex (sorbitol-positive) reference strain ATCC 49403 and $M$. fortuitum third biovariant complex (sorbitol-negative) reference strain ATCC 49935 as presented in Hogg et al. (1999).

A 1387 bp region of a 16S rRNA gene corresponding to Escherichia coli positions 109-1509 (GenBank accession number J01859) was determined for isolate $\mathrm{W} 4964^{\mathrm{T}}$. The $\mathrm{W} 4964^{\mathrm{T}}$ sequence was aligned with 18 other mycobacterial 16S rRNA sequences and with Nocardia otitidiscaviarum as the outgroup. The GenBank accession numbers and strain designations for the sequences used in the alignment are given in Table 1. Mycobacterium mageritense was not included in the alignment because of its incomplete $16 \mathrm{~S}$ sequence (634 bases). Regions in the alignment that were not represented in the majority of sequences were removed, resulting in a 971 base sequence consisting of regions 125-642, 892-1081 and 1109-1377 (E. coli numbering system). The multiple alignment was used as the input to a phylogeny inference software package (PHYLIP) and a phylogenetic tree was generated (Fig. 3). W4964 ${ }^{\mathrm{T}}$ was placed on a branch with $M$. peregrinum, and in a group with $M$. senegalense and $M$. fortuitum. Bootstrap analysis indicated that the branch consisting of $\mathrm{W} 4964^{\mathrm{T}}$ and $M$. peregrinum was robust (94\% of all possible errors), whereas the branch occupied by $M$. fortuitum, $M$. senegalense, isolate W4964 ${ }^{\mathrm{T}}$ and $M$. peregrinum occurred in $70 \%$ of the trees. The distance matrix generated from the edited alignment indicated that the $M$. peregrinum sequence was the most similar to that of W4964 ${ }^{\mathrm{T}}(99.58 \%)$; the $M$. senegalense sequence similarity value was $99 \cdot 26 \%$ and $M$. fortuitum was $98.85 \%$ similar. The remainder of the mycobacterial $16 \mathrm{~S}$ sequences were 93.58$98.22 \%$ similar to $\mathrm{W} 4964^{\mathrm{T}}$. In a pairwise comparison, M. mageritense was $97 \cdot 10 \%$ similar to $\mathrm{W} 4964^{\mathrm{T}}$ over a 621 base region.

The corrected $\mathrm{G}+\mathrm{C}$ content for isolate $\mathrm{W} 4964^{\mathrm{T}}$ was $64 \mathrm{~mol} \%$, placing it within the $61-71 \mathrm{~mol} \%$ range for Mycobacterium species as given by Takeuchi \& Hatano (1998).

The results of DNA-relatedness studies are given in Table 2. The levels of DNA hybridization between $M$. septicum catheter tip isolate $\mathrm{W} 4964^{\mathrm{T}}$ and the blood isolates were between $82 \%$ and $98 \%$ with a divergence of $0 \%$. The percentage relatedness between W4964 and the type strains of $M$. fortuitum, $M$. peregrinum and $M$. senegalense was $25 \%$ or less with divergence of $5 \cdot 0-5 \cdot 5 \%$. These results indicated that the four isolates represent a unique species, according to the phylogenetic definition of 'approximately $70 \%$ or greater DNA-DNA relatedness and with $5 \%$ or less $\Delta T_{\mathrm{m}}$ ' as given by Wayne et al. (1987). The name Mycobacterium septicum is proposed for the new species. 
Table 1. Strain designation and GenBank accession numbers for sequences in $16 \mathrm{~S}$ rRNA tree

\begin{tabular}{|c|c|c|}
\hline Organism & Strain & GenBank accession no. \\
\hline Mycobacterium abscessus & ATCC $19977^{\mathrm{T}}$ & $\mathrm{X} 82235$ \\
\hline Mycobacterium aichiense & ATCC $27280^{\mathrm{T}}$ & X55598 \\
\hline Mycobacterium aurum & ATCC $23366^{\mathrm{T}}$ & M29558 \\
\hline Mycobacterium avium & DSM 43216 & X52918 \\
\hline Mycobacterium chubuense & ATCC $27278^{\mathrm{T}}$ & X55596 \\
\hline Mycobacterium chelonae & ATCC $35752^{\mathrm{T}}$ & X82236 \\
\hline Mycobacterium diernhoferi & ATCC $19340^{\mathrm{T}}$ & X55593 \\
\hline Mycobacterium fortuitum & ATCC $6841^{\mathrm{T}}$ & X52933 \\
\hline Mycobacterium gilvum & ATCC $43909^{\mathrm{T}}$ & X55599 \\
\hline Mycobacterium mucogenicum & ATCC $49650^{\mathrm{T}}$ & X80771 \\
\hline Mycobacterium neoaurum & ATCC $25795^{\mathrm{T}}$ & M29564 \\
\hline Mycobacterium obuense & ATCC $27023^{\mathrm{T}}$ & X55597 \\
\hline Mycobacterium peregrinum & ATCC $14467^{\mathrm{T}}$ & AF130308 \\
\hline Mycobacterium phlei & ATCC $11758^{\mathrm{T}}$ & M29566 \\
\hline Mycobacterium senegalense & ATCC $35796^{\mathrm{T}}$ & M29567 \\
\hline Mycobacterium septicum & $\mathrm{W} 4964^{\mathrm{T}}$ & AF111809 \\
\hline Mycobacterium smegmatis & ATCC $14468^{\mathrm{T}}$ & X52922 \\
\hline Mycobacterium tuberculosis & NCTC $7416^{\mathrm{T}} \mathrm{H} 37 \mathrm{Rv}$ & X5889 \\
\hline Mycobacterium ulcerans & Unknown & X58954 \\
\hline Nocardia otitidiscaviarum & ATCC $14629^{\mathrm{T}}$ & M59056 \\
\hline
\end{tabular}

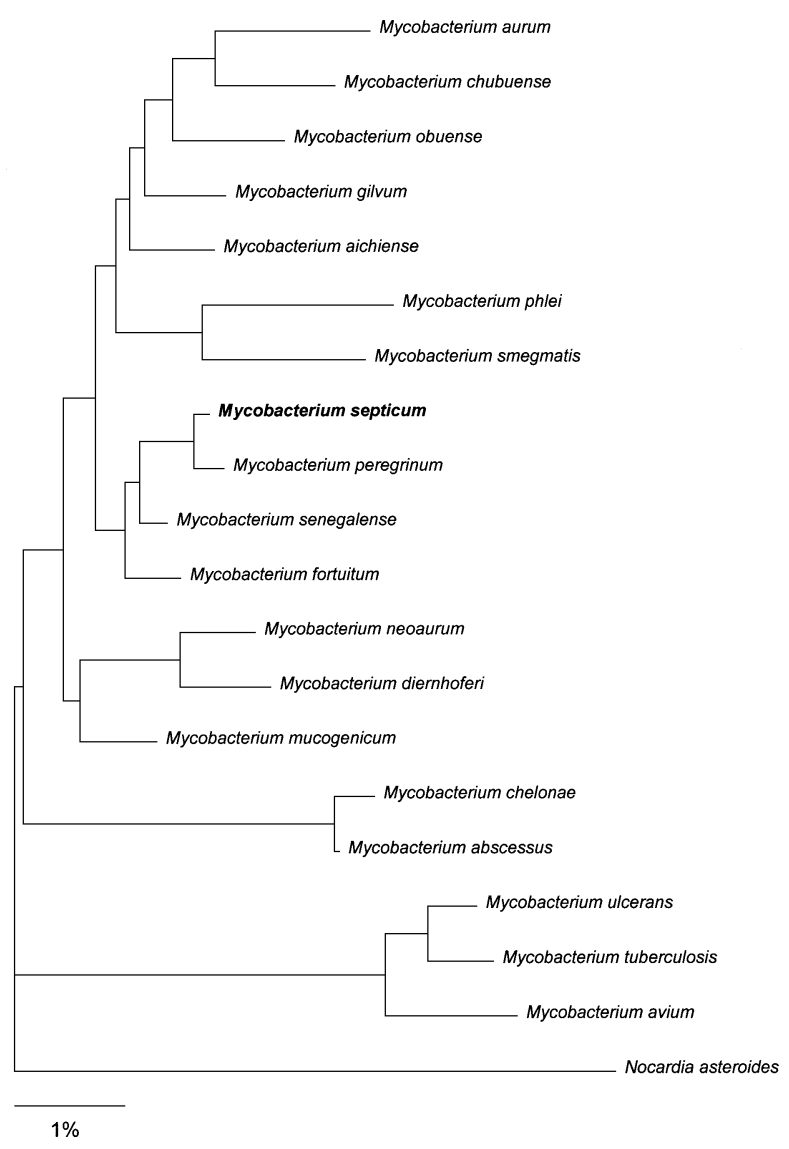

Fig. 3. Phylogenetic tree based on $16 \mathrm{~S}$ rRNA sequences showing the position of Mycobacterium septicum strain $\mathrm{W}^{4} 964^{\top}$. The tree was rooted by using Nocardia otitidiscaviarum as the outgroup. Mycobacterium mageritense is not shown. Scale bar, $1 \%$ difference in sequence.
Table 2. DNA relatedness of Mycobacterium septicum sp. nov. isolate $\mathrm{W} 4964^{\top}$ to the other Mycobacterium septicum isolates and Mycobacterium fortuitum, Mycobacterium peregrinum and Mycobacterium senegalense

\begin{tabular}{|lcc|}
\hline Source of unlabelled DNA & RBR $^{*}$ & Divergence \\
\hline
\end{tabular}

* Relative binding ratio [(percentage heterologous DNA bound to hydroxyapatite/percentage homologous DNA bound by hydroxyapatite $\times 100$ ] at $75^{\circ} \mathrm{C}$. All reactions were done at least twice.

$\dagger$ Divergence is the decrease in thermal stability (in degrees Celsius) of heterologous DNA duplexes compared with those of homologous DNA duplexes.

\section{Characteristics that differentiate M. septicum from related mycobacteria}

$M$. septicum can be distinguished from the type strains of $M$. fortuitum, $M$. peregrinum and $M$. senegalense by using a variety of biochemical and antimicrobial susceptibility tests. M. septicum differs from the type strain of $M$. fortuitum in that the former does not grow at $42{ }^{\circ} \mathrm{C}$, does not hydrolyse acetamide, does not have 3 -d arylsulfatase activity, but produces acid from D- 
Table 3. Phenotypic differences between the Mycobacterium septicum isolates and Mycobacterium fortuitum, Mycobacterium peregrinum and Mycobacterium senegalense

+ , Positive; -, negative.

\begin{tabular}{|c|c|c|c|c|}
\hline Characteristic & $\begin{array}{l}\text { M. fortuitum } \\
{\text { ATCC } 6841^{\mathrm{T}}}^{2}\end{array}$ & $\begin{array}{r}\text { M. peregrinum } \\
\text { ATCC } 14467^{\mathrm{T}}\end{array}$ & $\begin{array}{r}\text { M. senegalense } \\
\text { ATCC } 35796^{\mathrm{T}}\end{array}$ & $\begin{array}{c}M . \\
\text { septicum } \\
\text { isolates } \\
(n=4)\end{array}$ \\
\hline Growth at $42{ }^{\circ} \mathrm{C}$ & + & - & + & - \\
\hline Hydrolysis of acetamide & + & - & + & - \\
\hline Arylsulfatase activity at $3 \mathrm{~d}$ & + & + & + & $-*$ \\
\hline Utilization of citrate & - & - & + & - \\
\hline \multicolumn{5}{|l|}{ Acid production from: } \\
\hline D-Mannitol & - & + & + & + \\
\hline i-myo-Inositol & - & - & - & + \\
\hline \multicolumn{5}{|l|}{ Resistance to: $\dagger$} \\
\hline Erythromycin $(\mathrm{MIC} \geqslant 8 \mu \mathrm{g} / \mathrm{ml})$ & + & + & + & - \\
\hline Minocycline $(\mathrm{MIC} \geqslant 16 \mu \mathrm{g} / \mathrm{ml})$ & - & + & - & - \\
\hline $\begin{array}{l}\text { Sulfamethoxazole (MIC } \geqslant \\
32 \mu \mathrm{g} / \mathrm{ml})\end{array}$ & - & - & + & - \\
\hline Doxycycline $(\mathrm{MIC} \geqslant 16 \mu \mathrm{g} / \mathrm{ml})$ & - & + & - & - \\
\hline Vancomycin $(\mathrm{MIC} \geqslant 32 \mu \mathrm{g} / \mathrm{ml})$ & + & + & - & - \\
\hline Kanamycin (zone size $<15 \mathrm{~mm}$ ) & - & - & + & - \\
\hline Gentamicin (zone size $<20 \mathrm{~mm}$ ) & - & - & + & - \\
\hline Tobramycin (zone size $<20 \mathrm{~mm}$ ) & + & + & + & - \\
\hline Neomycin (zone size < 20 mm) & - & - & + & - \\
\hline
\end{tabular}

* All isolates are positive for arylsulfatase activity at $14 \mathrm{~d}$. Positive reactions may be detected at $3 \mathrm{~d}$ with other methods.

$\dagger$ The MIC breakpoints that were used are those of the National Committee for Clinical Laboratory Standards (1997). Disk contents were as follows: kanamycin $(30 \mu \mathrm{g})$, tobramycin $(10 \mu \mathrm{g})$ and neomycin $(30 \mu \mathrm{g})$. Zone sizes for resistance are those of Grange \& Stanford (1974).

mannitol and i-myo-inositol. Furthermore, $M$. septicum is susceptible to erythromycin, vancomycin and tobramycin. M. peregrinum and M. septicum differ in that $M$. peregrinum has 3-d arylsulfatase activity, does not produce acid from i-myo-inositol and is resistant to erythromycin, minocycline, doxycycline, vancomycin and tobramycin. $M$. septicum and $M$. senegalense can be differentiated in that $M$. senegalense grows at $42{ }^{\circ} \mathrm{C}$, hydrolyses acetamide, utilizes citrate, has 3-d arylsulfatase activity, does not produce acid from i-myo-inositol, and is resistant to erythromycin, sulfamethoxazole, kanamycin, gentamicin, tobramycin and neomycin. The phenotypic differences between $M$. septicum and the members of the $M$. fortuitum complex are given in Table 3 . In addition, genetic techniques such as ribotyping and 16S rRNA sequencing can be used to differentiate $M$. septicum as shown in Figs 2 and 3, respectively.

\section{Description of Mycobacterium septicum sp. nov.}

Mycobacterium septicum (sep'ti.cum. M.L. adj. for spread of bacteria in blood, referring to the condition from which this species was isolated).
This organism was isolated from and was the aetiological agent of catheter-related bacteraemia in a 2year-old child diagnosed with metastatic hepatoblastoma (Hogg et al., 1999). The cells are acid-fast, Gram-positive, pleomorphic coccobacilli. Longer filamentous forms are often observed but spores and capsules are absent. Colonies are cerebriform, slightly beige, with an irregular edge and do not demonstrate aerial hyphae. Growth occurs on Lowenstein-Jensen medium at $35{ }^{\circ} \mathrm{C}$ in less than $7 \mathrm{~d}$, at $28{ }^{\circ} \mathrm{C}$ in $5 \% \mathrm{NaCl}$ and on MacConkey agar without crystal violet. The isolates reduce nitrate, have arylsulfatase activity by $14 \mathrm{~d}$ and exhibit iron uptake. They do not hydrolyse acetamide, utilize citrate or grow in lysozyme. $M$. septicum produces acid from D-fructose, D-glucose, glycerol, i-myo-inositol, D-mannitol, D-mannose, salicin, D-trehalose and D-xylose, but not from adonitol, L-arabinose, cellobiose, dulcitol, i-erythritol, galactose, lactose, maltose, melibiose, raffinose, Lrhamnose, D-sorbitol, starch or sucrose. This organism is resistant to ampicillin, cefamandole, cefotaxime, ceftriaxone and streptomycin but susceptible to amikacin, amoxicillin-clavulanate, ciprofloxacin, doxycycline, erythromycin, imipenem, minocycline, 
sulfamethoxazole, trimethoprim-sulfamethoxazole, vancomycin, tobramycin, gentamicin, neomycin and kanamycin. $M$. septicum has a $\mathrm{G}+\mathrm{C}$ content of $64 \mathrm{~mol} \%$. The nearest phylogenetic neighbours of $M$. septicum by $16 \mathrm{~S}$ rRNA gene sequencing are $M$. peregrinum, $M$. senegalense and $M$. fortuitum. The type strain of $M$. septicum is $\mathrm{W} 4964^{\mathrm{T}}$, which was isolated from the catheter tip of a 2-year-old child with metastatic hepatoblastoma. This strain has been deposited in the DSMZ as DSM $44393^{\mathrm{T}}$ and in the ATCC as ATCC $700731^{\mathrm{T}}$.

\section{ACKNOWLEDGEMENTS}

We thank Robbin S. Weyant for his encouragement and support and Winfried Barchet for his assistance in sequencing. We thank Tanja Popovic, Centers for Disease Control and Prevention, Division of Bacterial and Mycotic Diseases, Meningitis and Special Pathogens Branch, for providing the digoxigenin-labelled set of five oligonucleotides that are complementary to bacterial $16 \mathrm{~S}+23 \mathrm{~S}$ rRNA gene sequences.

Use of trade names is for identification only and does not imply endorsement by the US Public Health Service or the US Department of Health and Human Services.

\section{REFERENCES}

Berd, D. (1973). Laboratory identification of clinically important aerobic actinomycetes. Appl Microbiol 25, 665-681.

Brenner, D. J., McWhorter, A. C., Knutson, J. K. \& Steigerwalt, A. G. (1982). Escherichia vulneris: a new species of Enterobacteriaceae associated with human wounds. J Clin Microbiol 15, 1133-1140.

Brenner, D. J., Hickman-Brenner, F. W., Lee, J. V. \& 7 other authors (1983). Vibrio furnissii (formerly aerogenic biogroup of Vibrio fluvialis), a new species isolated from human feces and the environment. J Clin Microbiol 18, 816-824.

Butler, W. R., Jost, K. C., Jr \& Kilburn, J. O. (1991). Identification of mycobacteria by high-performance liquid chromatography. J Clin Microbiol 29, 2468-2472.

Butler, W. R., Thibert, L. \& Kilburn, J. O. (1992). Identification of Mycobacterium avium complex strains and some similar species by high-performance liquid chromatography. J Clin Microbiol 30, 2698-2704.

Butler, W. R., Floyd, M. M., Silcox, V. A. \& 9 other authors (1996). Standardized method for HPLC identification of mycobacteria, 1996. Atlanta, GA: Centers for Disease Control and Prevention.

Domenech, P., Jimenez, M. S., Menendez, M. C., Bull, T. J., Samper, S., Manrique, A. \& Garcia, M. J. (1997). Mycobacterium mageritense sp. nov. Int J Syst Bacteriol 47, 535-540.

Grange, J. M. \& Stanford, J. L. (1974). Re-evaluation of Mycobacterium fortuitum (synonym: Mycobacterium ranae). Int $J$ Syst Bacteriol 24, 320-329.

Haas, W. H., Butler, W. R., Kirschner, P. \& 9 other authors (1997). A new agent of mycobacterial lymphadenitis in children: Mycobacterium heidelbergense sp. nov. J Clin Microbiol 35, 3203-3209.
Hogg, G. G., Schinsky, M. F., McNeil, M. M., Lasker, B. A., Silcox, V. A. \& Brown, J. M. (1999). Central line sepsis in a child due to a previously unidentified mycobacterium. J Clin Microbiol 37, 1193-1196.

Jukes, T. H. \& Cantor, C. R. (1969). Evolution of protein molecules. In Mammalian Protein Metabolism, vol. 3, pp. 21-132. Edited by H. N. Munro. New York: Academic Press.

Kiehlbauch, J. A., Plikaytis, B. D., Swaminathan, B., Cameron, D. N. \& Wachsmuth, I. K. (1991). Restriction fragment length polymorphisms in the ribosomal genes for species identification and subtyping of aerotolerant Campylobacter species. J Clin Microbiol 29, 1670-1676.

Lasker, B. A., Brown, J. M. \& McNeil, M. M. (1992). Identification and epidemiological typing of clinical and environmental isolates of the genus Rhodococcus with use of a digoxigeninlabeled rDNA gene probe. Clin Infect Dis 15, 223-233.

Loeffelholz, M. J. \& Scholl, D. R. (1989). Method for improved extraction of DNA fro Nocardia asteroides. J Clin Microbiol 27, 1880-1881.

Mandel, M., Igambi, L., Bergendahl, J., Dodson, M. L., Jr \& Scheltgen, E. (1970). Correlation of melting temperature and cesium chloride buoyant density of bacterial deoxyribonucleic acid. J Bacteriol 101, 333-338.

National Committee for Clinical Laboratory Standards (1997). Methods for dilution antimicrobial susceptibility tests for bacteria that grow aerobically. Approved standard M7-A4. Wayne, PA: National Committee for Clinical Laboratory Standards.

Popovic, T. C., Bopp, C. A., Olsvik, O. \& Kiehlbauch, J. (1993). Ribotyping in molecular epidemiology. In Diagnostic Molecular Microbiology, pp. 573-583. Edited by D. H. Persing, T. F. Smith, F. C. Tenover \& T. J. White. Washington, DC: American Society for Microbiology.

Regnault, B., Grimont, F. \& Grimont, P. A. D. (1997). Universal ribotyping method using a chemically-labeled oligonucleotide probe mixture. Res Microbiol 148, 649-659.

Sack, J. B. (1990). Disseminated infection due to Mycobacterium fortuitum in a patient with AIDS. Rev Infect Dis 12, 961-963.

Saitou, N. \& Nei, M. (1987). The neighbor-joining method: a new method for reconstructing phylogenetic trees. Mol Biol Evol 4, 406-425.

Silcox, V. A., Good, R. C. \& Floyd, M. M. (1981). Identification of clinically significant Mycobacterium fortuitum complex isolates. $J$ Clin Microbiol 14, 686-691.

Stackebrandt, E. \& Charfreitag, O. (1990). Partial 16S rRNA primary structure of five Actinomyces species: phylogenetic implications and development of an Actinomyces israeliispecific oligonucleotide probe. J Gen Microbiol 136, 37-43.

Takeuchi, M. \& Hatano, K. (1998). Gordonia rhizosphera sp. nov., isolated from the mangrove rhizosphere. Int J Syst Bacteriol 48, 607-612.

Wallace, R. J., Jr, Brown, B. A., Silcox, V. A. \& 8 other authors (1991). Clinical disease, drug susceptibility, and biochemical patterns of the unnamed third biovariant complex of Mycobacterium fortuitum. J Infect Dis 163, 598-603.

Wayne, L. G., Brenner, D. J., Colwell, R. R. \& 9 other authors (1987). International Committee on Systematic Bacteriology. Report of the ad hoc committee on reconciliation of approaches to bacterial systematics. Int J Syst Bacteriol 37, 463-464. 